\title{
The impact of brain drain on human capital in developing countries
}

\begin{abstract}
The debate over the effect of human capital flight on educational attainment in immigrants' source countries has received huge theoretical propositions but a few analytical approaches. This paper examines the short-run and long-run impact of skilled migration rates (brain drain) on human capital formation in migrants' source developing countries. Specifically, we revisited some empirical studies that found evidence of beneficial brain drain in migrants' source countries. Our empirical result, using school enrolments does not only disagree with theirs but also presents an insight on how human capital leakages that occur through brain drain can be counterbalanced through remittances received in the immigrants' source countries.
\end{abstract}

Keyword: Brain drain; Human capital; Remittance 